\title{
OPEN A population-based study of self-reported adverse drug events among Lebanese outpatients
}

\author{
Elsy Ramia $\mathbb{1}^{1,8} \llbracket$, Rony M. Zeenny ${ }^{2,8}$, Souheil Hallit $\mathbb{1}^{3,4,5}$ \& Pascale Salameh $\mathbb{1}^{5,6,7}$
}

There is a limited number of studies assessing the epidemiology of Adverse Drug Events (ADEs) in the outpatient setting, especially those that do not result in healthcare use. The primary objective of this study was to assess the prevalence and determinants of self-reported ADEs among Lebanese outpatients. It was a cross-sectional observational study performed among Lebanese outpatients visiting community pharmacies across Lebanon. A questionnaire was designed to elicit patients' relevant information. The association between categorical variables were evaluated using Pearson $\chi^{2}$ test or Fisher's exact test. Binary logistic regression was performed to identify factors that affect the experience of self-reported ADEs. The study comprised 3148 patients. Around $37 \%$ of patients reported experiencing an ADE in the previous year. When ADEs occur, $70.5 \%$ of the respondents reported informing their physicians. Increasing number of medications per patient, use of injectable medication, and inquiring about potential drug-drug interactions were associated with higher experience of $\operatorname{ADEs}(p=0.049 ; p=0.003$; and $p=0.009$ respectively). Patients who received hospital discharge counseling reported experiencing less ADEs $(p=0.002)$. Our study showed prevalence of ADEs among Lebanese outpatients especially patients with polypharmacy, and highlighted the need to educate patients about the importance of reporting ADEs to their physicians.

Patient safety is a serious public health concern across the world. According to the World Health Organization (WHO), "there is a 1 in 300 chance of a patient being harmed during health care" ${ }^{1}$. Adverse drug events (ADEs) are the most common type of adverse events experienced by patients ${ }^{2}$. An $\mathrm{ADE}$ is "any injury occurring during the patient's drug therapy and resulting either from appropriate care, or from unsuitable or suboptimal care". Hence, ADEs include the adverse drug reactions (ADRs) occurring during normal use of the medicine, and any harm secondary to a medication error or inappropriate medication use $\mathrm{e}^{3,4}$. Although estimates of the incidence of ADEs vary depending on the setting, the population, and the method of assessment used, ADEs remain an important cause of morbidity, mortality and wasted expenditure $\mathrm{e}^{5,6}$.

There are several reliable methods to collect ADEs. These methods comprise spontaneous reporting through national pharmacovigilance databases, collecting practice data, soliciting events from healthcare professionals, direct observation, and surveying patients for drug-related events ${ }^{7,8}$.

In fact, patients' role in reporting ADEs is well recognized and the merits of patient reports are considered internationally ${ }^{9}$. The European Medicines Agency (EMA) and the United States Food and Drug Administration (US FDA) have made it possible for patients to report suspected ADEs directly through their national reporting databases ${ }^{8,10}$. Patients are encouraged to act as "vigilant partners" in their own care as they can decrease the risk of drug therapy ${ }^{9,11}$. Despite some limitations including reports from patients complement professionals' reports, and can trigger major considerations, labelling changes, or drug withdrawal from the market ${ }^{12,13}$.

Similarly, patient surveys are an important and reliable method to detect ADEs in the outpatient setting. Outpatients' ADEs are often under-reported, poorly documented, and not confirmed by a healthcare professional ${ }^{14,15}$.

\footnotetext{
${ }^{1}$ Department of Pharmacy Practice, School of Pharmacy, Lebanese American University, P.O. Box S-23, Byblos, Lebanon. ${ }^{2}$ Department of Pharmacy, American University of Beirut-Medical Center, 236, Riad El Solh, P.O.Box11, 1107-2020 Beirut, Lebanon. ${ }^{3}$ Faculty of Medicine and Medical Sciences, Holy Spirit University of Kaslik (USEK), Jounieh, Lebanon. ${ }^{4}$ Research Department, Psychiatric Hospital of the Cross, Jal Eddib, Lebanon. ${ }^{5}$ INSPECT-LB: National Institute of Public Health, Clinical Epidemiology and Toxicology, Beirut, Lebanon. ${ }^{6}$ Faculty of Pharmacy, Lebanese University, Beirut, Lebanon. ${ }^{7}$ Faculty of Medicine, University of Nicosia, Nicosia, Cyprus. ${ }^{8}$ These authors contributed equally: Elsy Ramia and Rony M. Zeenny. ${ }^{\varpi}$ email: elsy.ramia@lau.edu.lb
} 
In contrast to inpatients, outpatients are responsible for both obtaining and administering their medications, and tend to have longer duration of treatment. Furthermore, outpatients often have more than one prescriber, less regular contact with their physicians and far less monitoring compared with hospitalized patients ${ }^{14,16}$.

There is a limited number of studies assessing the epidemiology of ADEs in the outpatient setting, especially the ADEs that do not result in healthcare use $\mathrm{e}^{17,18}$. Few published studies examined ADEs from the patients' perspective, and aimed at estimating the prevalence and assessing risk factors of self-reported ADEs across Europe, the United States and Australia ${ }^{19-23}$. Additional studies highlighted poor patient awareness as a main barrier for outpatient reporting of ADRs ${ }^{24,25}$.

In Lebanon, the financial constraints, fragmented care, and easy accessibility of medications, potentially increase the risk of inappropriate medication use and adverse drug events ${ }^{26}$. Cross-sectional studies conducted among Lebanese outpatients found potentially inappropriate medication use ${ }^{27-29}$, incomplete performance of follow-up monitoring ${ }^{30}$, and suboptimal patient knowledge of their prescribed medications' ADRs ${ }^{31}$. Other studies also highlighted a poor reporting culture among Lebanese medical staff and suboptimal pharmacovigilance awareness $^{32-35}$.

Lastly, Lebanese pharmacists working in community settings reported being aware of ADRs occurring with various medications post-marketing, yet were currently unable to disseminate this information or record it centrally, in the absence of an active national reporting system ${ }^{36}$.

There is a lack of studies addressing outpatients' experience of ADEs in Lebanon. The primary objective of this study was to assess the prevalence and risk factors of self-reported Adverse Drug Events among Lebanese outpatients. A secondary objective was to assess the counseling outpatients received from their primary caregivers in the community and upon hospital discharge when applicable.

\section{Methods}

A cross-sectional questionnaire-based observational study was performed between March and May 2016, among Lebanese outpatients visiting a community pharmacy. Patients were eligible for the study if they were Lebanese adults, receiving one or more medication, and willing to participate in the study.

Data collection tool. The investigators derived the questionnaire from the National Health Service-England (NHS) inpatient survey program, the WHO "Patient Questionnaire about Medication Safety" 37,38 , and other studies of self-reported ADEs ${ }^{14,20,39}$. The investigators then adapted the questionnaire to the Lebanese context and added many questions to align with the study objectives. The questionnaire addressed the participants' sociodemographic characteristics, medical condition, outpatient risk-associated behaviors, experience of ADEs, and hospitalization during the previous year (if any).

Throughout the questionnaire, investigators measured frequency using a five-point Likert scale with answer categories ranging from always to never. The questionnaire was first developed in English, and was then translated into Arabic using a forward-backward translation process for validation. Before administration, the questionnaire was pilot-tested for clarity and content validity in different populations, including health professionals, nonprofessionals, and the elderly.

Assessing self-reported ADEs. Patients' experience of ADEs was assessed by asking the patients whether they experienced "any problems or symptoms" after taking their medication(s) within the past year. Since our adopted definition for ADEs includes both ADRs and medication errors, and since the medication administration in the outpatient setting is under the control of the patient, the distinction between an ADR and a medication error is not straightforward and cannot be assessed using a simple self-administered questionnaire. Therefore, the investigators opted to ask about any "symptoms/problems" the patient could have experienced after medication administration, as a general question that includes either an ADR or a potential medication error. The questionnaire also included questions about the outcome of the most serious symptom/problem that patients had, and about reporting these symptoms to their physicians ${ }^{20}$.

Data collection process. Inspectors affiliated with the Order of Pharmacists of Lebanon (OPL) performed the data collection. The study investigators trained fourteen OPL inspectors, all pharmacists, in a 4-hour session that included a general overview of ADEs, instructions on how to include participants in the study, and a review of the questionnaire.

The investigators obtained a list of all active community pharmacies in Lebanon from the OPL. Using convenience sampling, the investigators selected a sample of 1574 community pharmacies across Lebanon for patient encounters. The OPL inspectors visited each pharmacy for a maximum of one hour. In each pharmacy, one inspector approached patients asking for their willingness to participate, and described the objective of the study and the estimated time to complete the questionnaire. The inspector highlighted that participation in the study is voluntary and strictly confidential. The first two patients visiting the pharmacy during the inspector's presence and agreeing to participate were included. The questionnaire was self-administered.

Ethical approval and consent to participate. The study was performed in accordance with the ethical standards as laid down in the 1964 Declaration of Helsinki and its later amendments. Before initiation of the data collection, the approval of the Lebanese American University Institutional Review Board (LAU IRB) was sought as appropriate. IRB registration number: \#IRB00006954 LAUIRB\#1. Accordingly, all participants provided informed oral consent prior to participation. 
Data management and statistical analysis. No quantitative data exists for the experience of ADEs in the Lebanese population. The investigators based their sample size estimation on a study performed among 7099 Swedish adults, where ADEs were reported by $19.4 \%$ of the respondents ${ }^{20}$. Estimating the Lebanese population size to be around $5,000,000^{40}$, we defined our goal to interview a minimum sample size of 920 patients from 460 community pharmacies. This sample size is powered to provide $95 \%$ confidence level.

The data was analyzed using SPSS version 23 software. Descriptive statistics were used to calculate and report all participants' responses. For all the analysis, the five-point Likert scale was dichotomized into Yes (always/ very often/sometimes) and No (rarely/never). The association between categorical variables were evaluated using Pearson $\chi^{2}$ test or Fisher's exact test where the expected cell count was less than 5. Binary logistic regression was performed to identify factors that were associated with the self-reported experience of ADEs (dichotomized), using a Backward LR method. Variables with a $p$-value of 0.2 or less in the bivariate analysis were included in the final models. A $p$-value of less than 0.05 was considered significant.

\section{Results}

The study comprised 3148 patients from different geographical areas around Lebanon. The study acceptance rate was $78 \%$. Patients denied participation due to lack of time or no interest.

Study participants had almost equal gender distribution and had a mean age of 54.33 years (SD 16.03). When examining patients' medical conditions, around $20 \%$ of the study participants reported having 3 or more concomitant chronic diseases, and around $14 \%$ taking 5 or more medications/day (Table 1).

Self-reported ADEs. Around $37 \%$ of our patient population reported experiencing an ADE. While $18.7 \%$ of the ADEs were mild requiring no change in therapy, the most serious ADEs experienced by the patient resulted in dose reduction (18.1\%), change of therapy (42.1\%), hospitalization $(5.1 \%)$ or long-term complications (1.5\%). When ADEs occur, 70.55\% of the respondents reported informing their physicians. Among the 344 patients who reported not informing their physicians about their ADEs, around 17\% reported being unable to reach their physicians to report ADEs, $16 \%$ were not educated to report ADRs as they occur, and $14.8 \%$ reported that their physicians are not usually welcoming to discuss their concerns (Table 2).

In the multivariable analysis, several variables were significantly associated with patients' reported experience of ADEs. Increasing number of medications taken at home every day was significantly associated with higher experience of ADEs $(\mathrm{ORa}=1.225, p=0.049)$. Patients who reported using an injectable medication $(\mathrm{ORa}=3.008$, $p=0.003)$ and those who asked their pharmacists about the possible interactions with prescribed medications while getting the OTC (Over-the-counter) medications from the pharmacy $(\mathrm{ORa}=1.945, p=0.009)$ reported experiencing more ADEs. Patients who received counseling from their physicians regarding missing drug doses, and for whom a member of hospital staff explained how to take the medications in an understandable way before hospital discharge reported experiencing less ADEs ( $\mathrm{ORa}=0.439, p=0.004$; and $\mathrm{ORa}=0.430, p=0.002$ respectively). The variables "physician assessing medication history before prescribing a new medication" and "physician inquiring about previous ADRS before prescribing a new medication" remained in the final model with a non-significant p-value of 0.075 and 0.088 respectively. Having any of the chronic disease did not significantly affect the experience of ADEs (Table 3).

Other outcomes. Outpatients' medication-related practices. The study participants reported several suboptimal medication-related practices. Around $12 \%$ of the study population reported acquiring their medications from different community pharmacies, and around $80 \%$ reported not considering counseling services when selecting their community pharmacy of choice. In terms of medication administration, the majority of participants reported using non-calibrated measures for intake of liquid medications ( $81 \%$ for teaspoon and tablespoon); and around $12 \%$ reported having a neighbor/relative administer injectable medications. At the level of drug information, around 36\% reported not discussing the medications they take each time they visit the physicians, around $61 \%$ reported not reading the leaflet of each medication they take, and around half of the patients didn't ask about the possible interactions between the over-the-counter drugs and the medications they take.

Around $88 \%$ of the patients reported not taking a prescribed medication because of contraindications mentioned in the leaflet and not mentioned by the physician during the visit (Table 4).

Counseling provided by healthcare providers regarding elements of medication use. Significantly more patients reported receiving counseling from pharmacists as compared to physicians regarding elements of medication use: drug interactions $(78.4 \%$ vs $34.3 \%, p<0.001)$; missing drug doses $(55.7 \%$ vs $31.4 \%, p<0.001)$; accidental overdose $(49.9 \%$ vs $28.7 \%, p<0.001)$; and potential ADRs $(67.1 \%$ vs $38.8 \%$; $p<0.001)$. While $73.5 \%$ of our patient population reported that physicians assessed their medication history before prescribing a new drug, only $49.7 \%$ reported physicians inquiring about previous ADRs before prescribing a new medication (Table 5).

Hospitalization in the previous year. Around 23\% of our patient population reported hospitalization in the previous year, with a mean length of stay of 5.2 days ( \pm 2.8 days). The majority of hospitalized patients $(85 \%)$ reported being prescribed medications upon discharge, with $71.6 \%$ of them being informed by a healthcare provider about the purpose of the medications and how to take it. Only $27.8 \%$ of patients reported being counseled about ADRs of the prescribed medications, and $56.1 \%$ being given written or printed medication information upon discharge (Table 6). 


\begin{tabular}{|c|c|}
\hline Characteristic & Frequency $(\%)^{\mathrm{a}}$ \\
\hline \multicolumn{2}{|l|}{ Gender } \\
\hline Male & $1550(49.2)$ \\
\hline Female & $1559(49.5)$ \\
\hline Age (mean in years \pm SD) & $54.33 \pm 16.03$ \\
\hline \multicolumn{2}{|l|}{ Marital status } \\
\hline Single & $464(14.7)$ \\
\hline Married & $2350(74.7)$ \\
\hline Widowed & $261(8.3)$ \\
\hline Divorced & $42(1.3)$ \\
\hline \multicolumn{2}{|l|}{ Level of education } \\
\hline Illiterate & $187(5.9)$ \\
\hline Some school & $936(29.7)$ \\
\hline High school & $1156(36.8)$ \\
\hline Bachelor degree & $488(15.5)$ \\
\hline Master's degree & $232(7.4)$ \\
\hline Doctoral degree & $70(2.2)$ \\
\hline \multicolumn{2}{|l|}{ Employment status } \\
\hline Student & $61(1.9)$ \\
\hline Self-employed & $686(21.8)$ \\
\hline Employed & $802(25.5)$ \\
\hline Unemployed & $983(31.2)$ \\
\hline Retired & $455(14.5)$ \\
\hline \multicolumn{2}{|l|}{ Geographic area of residence } \\
\hline Beirut & $523(16.6)$ \\
\hline Mount Lebanon & $1486(47.2)$ \\
\hline North & $180(5.7)$ \\
\hline Bekaa & $495(15.7)$ \\
\hline South/Nabatiyye & $438(13.9)$ \\
\hline \multicolumn{2}{|c|}{ Number of Chronic Diseases per patient } \\
\hline 1 & $1693(53.8)$ \\
\hline 2 & $714(22.7)$ \\
\hline$\geq 3$ & $635(20.2)$ \\
\hline \multicolumn{2}{|c|}{ Number of medications taken at home every day } \\
\hline 1 & $371(11.8)$ \\
\hline 2 & $598(19.0)$ \\
\hline 3 & $981(31.2)$ \\
\hline 4 & $615(19.5)$ \\
\hline$\geq 5$ & $432(13.7)$ \\
\hline \multicolumn{2}{|l|}{ Chronic diseases (most common) } \\
\hline Hypertension & $1399(44.4)$ \\
\hline Dyslipidemia & $992(31.5)$ \\
\hline Diabetes Mellitus & $840(26.7)$ \\
\hline Rheumatoid Arthritis & $280(8.9)$ \\
\hline Asthma/COPD & $237(7.5)$ \\
\hline Chronic Heart Failure & $144(4.6)$ \\
\hline Depression & $50(1.6)$ \\
\hline Osteoporosis & $41(1.3)$ \\
\hline Intake of any oral liquid medication & $170(5.4)$ \\
\hline Intake of any inhaled medication & 209 (6.6) \\
\hline Intake of any patch medication & $24(0.8)$ \\
\hline Intake of any injectable medication & $227(7.2)$ \\
\hline
\end{tabular}

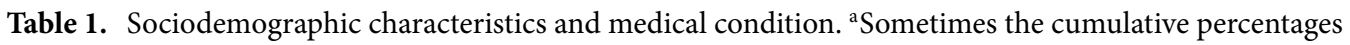
may not reach $100 \%$ due to missing values. When missing values are less than $10 \%$, they were not reported explicitly. 


\begin{tabular}{|c|c|}
\hline Outcome & Frequency $(\%)^{a}$ \\
\hline \multicolumn{2}{|l|}{ Patients' self-reported experience of ADEs } \\
\hline Yes & $1168(37.1)$ \\
\hline No & $1980(62.9)$ \\
\hline \multicolumn{2}{|c|}{ Main outcome of most serious ADE (for those who answered yes on question 1) } \\
\hline Mild reaction, No change in therapy & $219(18.7)$ \\
\hline Reaction required dose reduction & $211(18.1)$ \\
\hline Reaction required change of therapy & $492(42.1)$ \\
\hline Reaction required treatment & $44(3.8)$ \\
\hline Reaction required hospitalization & $59(5.1)$ \\
\hline Reaction resulted in a long term complication & $18(1.5)$ \\
\hline Missing answer & $125(10.7)$ \\
\hline \multicolumn{2}{|c|}{ Informing the physician when ADEs occur (for those who answered yes on question 1) } \\
\hline Yes & $824(70.55)$ \\
\hline No & $344(29.45)$ \\
\hline \multicolumn{2}{|c|}{ Reason for not informing the physician about ADEs (for those who answered No on question 2) } \\
\hline Mild reaction, no need to inform physician & $167(48.55)$ \\
\hline Unable to reach the physician & $59(17.15)$ \\
\hline Physician did not inform patient to report in case of ADR & $55(15.99)$ \\
\hline Physician not usually welcoming to discuss patient's concerns & $51(14.82)$ \\
\hline
\end{tabular}

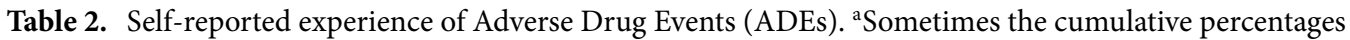
may not reach $100 \%$ due to missing values. When missing values are less than $10 \%$, they were not reported explicitly.

\begin{tabular}{|c|c|c|c|}
\hline Variable $^{a}$ & ORa & Confidence interval & $P$-value \\
\hline \multicolumn{4}{|l|}{ Geographic area of residence (Beirut is the reference) } \\
\hline Mount Lebanon & 0.498 & $0.262-0.948$ & 0.034 \\
\hline North & 2.840 & $0.502-16.071$ & 0.238 \\
\hline Bekaa & 1.105 & $0.508-2.399$ & 0.802 \\
\hline South/Nabatiyye & 0.378 & $0.091-1.571$ & 0.181 \\
\hline Number of medications taken at home every day & 1.225 & $1.001-1.499$ & 0.049 \\
\hline Intake of any injectable medication & 3.008 & $1.465-6.177$ & 0.003 \\
\hline $\begin{array}{l}\text { Asking about possible interactions with prescribed medications while getting over-the-counter } \\
\text { medications from the pharmacy }\end{array}$ & 1.945 & $1.183-3.199$ & 0.009 \\
\hline Physician providing counseling about missing doses & 0.439 & $0.251-0.768$ & 0.004 \\
\hline Physician assessing medication history before prescribing a new medication & 1.730 & $0.947-3.162$ & 0.075 \\
\hline Physician inquiring about previous ADRs before prescribing a new medication & 1.599 & $0.932-2.742$ & 0.088 \\
\hline $\begin{array}{l}\text { A member of hospital staff explaining to the patient how to take the medications in an under- } \\
\text { standable way before hospital discharge }\end{array}$ & 0.430 & $0.252-0.733$ & 0.002 \\
\hline
\end{tabular}

Table 3. Patients' self-reported experience of Adverse Drug Events (ADEs)-Multivariable Analysis. ${ }^{a}$ Variables with a $p$-value of 0.2 or less in the bivariate analysis were included in the initial model. Those include: gender; marital status; level of education; geographic area of residence; employment status; number of chronic diseases per patient; chronic kidney disease; intake of any inhaled medication; intake of any injectable medication; initiation of medication-related discussion; not taking a prescribed medication because of counter-indications mentioned in the leaflet and not mentioned by the physician during the visit; asking about possible interactions with prescribed medications while getting the OTC's from the pharmacy; pharmacist providing counseling about drug interactions, missing doses, accidental overdose, and potential ADRs; physician providing counseling about drug interactions, missing doses, accidental overdose, and potential ADRs; physician assessing medication history before prescribing a new medication; physician inquiring about previous ADRs before prescribing a new medication; hospitalization in the previous year; a member of hospital staff explaining to the patient the purpose of the medications to be taken at home in an understandable way; a member of hospital staff explaining to the patient how to take the medications in an understandable way. Categorical variables identified: level of education, geographic area of residence, employment status, initiation of medication-related discussion. Using a Backward LR method, the model finally retained the variables shown in this table. Hosmer and Lemshow test for sample adequacy $p$-value: 0.451. Nagelkerke model summary 0.223 . 
Source of medication acquisition

Same pharmacy

Different pharmacies

375 (11.9)

Other

51 (1.6)

Preference for pharmacy selection (check all that apply)

Trust the pharmacist

$2056(65.3)$

Insurance selection

Proximity to house/work

$72(2.3)$

Easy access and parking

Discount

Counseling

Tools used to measure liquid dose of medication

Teaspoon

Tablespoon

Calibrated cup/syringe

1458 (46.3)

$242(7.7)$

$106(3.4)$

$648(20.6)$

Administration of injectable medication performed by

\begin{tabular}{ll|l} 
Self & $90(41.1)$
\end{tabular}

Neighbor/relative

$26(11.9)$

Pharmacist

$69(31.6)$

Physician/nurse at home

$24(11.0)$

Healthcare provider in outpatient clinics

$10(4.6)$

Discussion of prescribed medications with physician during visit/consultation

\begin{tabular}{|l|l|l}
\hline Yes & $1915(60.8)$ \\
\hline No & $1145(36.4)$
\end{tabular}

Initiation of medication-related discussion

\begin{tabular}{|l|l|l|l|l}
\hline Physician & $1104(35.1)$ & $1636(52.0)$ \\
\hline Patient & $290(9.2)$ \\
\hline Accompanying person & $1162(36.9)$ \\
\hline Reading the leaflet of each medication & $1911(60.7)$ \\
\hline Yes & & \\
\hline No & & \\
\hline
\end{tabular}

Not taking a prescribed medication because of counter-indications mentioned in the leaflet and not mentioned by the physician during the visit

\begin{tabular}{|l|l|l|}
\hline Yes & $278(8.8)$ \\
\hline No & $2772(88.1)$ \\
\hline Asking about possible interactions with prescribed medications while getting the OTC's from the pharmacy & $1420(45.1)$ \\
\hline Yes & $1648(52.4)$ & \\
\hline No &
\end{tabular}

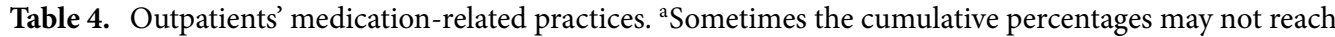
$100 \%$ due to missing values. When missing values are less than $10 \%$, they were not reported explicitly.

\begin{tabular}{|l|l|l|l|}
\hline Outcome & Physician n (\%) $^{\mathbf{a}}$ & Pharmacist n (\%) $^{\mathbf{a}}$ & $\boldsymbol{P}$-value \\
\hline Providing counseling about drug interactions & $1080(34.3)$ & $2468(78.4)$ & $<0.001$ \\
\hline Providing counseling about what to when missing a drug dose & $988(31.4)$ & $1754(55.7)$ & $<0.001$ \\
\hline Providing counseling about accidental overdose & $904(28.7)$ & $1571(49.9)$ & $<0.001$ \\
\hline Providing counseling about potential ADRs & $1221(38.8)$ & $2112(67.1)$ & $<0.001$ \\
\hline Assessing medication history before prescribing a new medication & $2315(73.5)$ & & \\
\hline Inquiring about previous ADRs before prescribing a new medication & $1564(49.7)$ & & \\
\hline
\end{tabular}

Table 5. Counseling provided by healthcare providers regarding elements of medication use. ${ }^{\text {a Sometimes the }}$ cumulative percentages may not reach $100 \%$ due to missing values. When missing values are less than $10 \%$, they were not reported explicitly. 


\begin{tabular}{|c|c|}
\hline Outcome & Frequency $(\%)^{\mathrm{a}}$ \\
\hline \multicolumn{2}{|c|}{ Hospitalization in the previous year } \\
\hline No & $2335(74.2)$ \\
\hline Yes & $710(22.6)$ \\
\hline \multicolumn{2}{|c|}{ Length of hospital stay } \\
\hline Mean & 5.18 days \\
\hline Minimum & 1 day \\
\hline Maximum & 17 days \\
\hline SD & 2.84 \\
\hline \multicolumn{2}{|c|}{ Admission to a critical care area (ICU/CCU/CSU) ${ }^{b}$} \\
\hline No & $563(79.5)$ \\
\hline Yes & $145(20.5)$ \\
\hline \multicolumn{2}{|c|}{ Patient prescribed medications upon discharge ${ }^{b}$} \\
\hline No & $105(14.8)$ \\
\hline Yes & $605(85.2)$ \\
\hline \multicolumn{2}{|c|}{ A member of staff explaining to the patient the purpose of the medications to be taken at home in an understandable wayc } \\
\hline No & $172(28.4)$ \\
\hline Yes & $433(71.6)$ \\
\hline \multicolumn{2}{|c|}{ A member of staff explaining to the patient how to take the medications in an understandable way ${ }^{c}$} \\
\hline No & $172(28.4)$ \\
\hline Yes & $433(71.6)$ \\
\hline \multicolumn{2}{|c|}{ A member of staff explaining to the patient about ADRs to watch for ${ }^{c}$} \\
\hline No & $436(72.2)$ \\
\hline Yes & $168(27.8)$ \\
\hline \multicolumn{2}{|c|}{ Given written or printed information about medications upon discharge $\mathrm{e}^{\mathrm{c}}$} \\
\hline No & $265(43.9)$ \\
\hline Yes & $338(56.1)$ \\
\hline
\end{tabular}

Table 6. Hospitalization in the previous year. a Sometimes the cumulative percentages may not reach $100 \%$ due to missing values. When missing values are less than $10 \%$, they were not reported explicitly. ${ }^{\mathrm{b}}$ Total number of participants on the marked questions is 710 , referring to the patients who were hospitalized during the last year. ${ }^{\mathrm{c} T o t a l}$ number of participants on the marked questions is 605 , referring to the patients who were prescribed medications upon hospital discharge.

\section{Discussion}

In this cross-sectional questionnaire-based study, around $37 \%$ of our patient population reported experiencing an $\mathrm{ADE}$ within the previous year. When ADEs occur, $70.5 \%$ of the respondents reported informing their physicians.

As previously mentioned, there are several reliable methods to collect patient ADEs. Different methods of collecting patient data regarding adverse events (i.e. patient surveys versus spontaneous reporting) lead to large differences in the reported rates of these adverse events, reducing the validity and meaningfulness of comparisons ${ }^{41}$. In this discussion, the authors opted to compare the results with findings of other patient survey studies.

The rate of ADEs reported by our study participants was similar to the findings of a recently published questionnaire-guided study of 1190 ambulatory adult patients in Nigeria ${ }^{42}$, but higher than previously published rates of self-reported $\mathrm{ADEs}^{20-22}$. In fact, the percentage of self-reported ADEs in questionnaire-based studies depends on the definition of ADEs adopted and the timespan specified for the reported $\mathrm{ADEs}^{20-22}$. In a study by Oladimeji et al. assessing self-reported ADEs among elderly US residents enrolled in Medicare, $18 \%$ of the respondents reported an $\mathrm{ADE}$ in the past year ${ }^{22}$. In that study, authors defined an ADE as the patient visiting a physician to report an unwanted reaction or medicine problem ${ }^{22}$. This can explain the higher percentage reported in our study, since we inquired about any $\mathrm{ADE}$, even if it did not lead to a physician's visit. In a study by Hakkarainen et al. that aimed to assess the 1-month prevalence of self-reported ADEs among the adult public in Sweden, 19.4\% of the respondents reported experience of $\mathrm{ADEs}^{20}$. This lower percentage can be explained by the 1-month timespan specified. In another population based-study in Sweden by Hedna et al., the authors reasoned that the low reported ADRs percentages (2.5\%) could reflect a lack of patient awareness for symptoms of $\mathrm{ADRs}^{43}$. In fact, many ADEs are likely never reported because they are not recognized ${ }^{8}$. Lastly, in a national cross-sectional study assessing community-based ADRs in Saudi Arabia, the sample prevalence of ADRs was around 23\%. Authors, however, did not assess ADEs in that survey which does not compare with our study ${ }^{44}$.

Early identification of ADEs and factors associated with them may help physicians prevent and resolve these $\mathrm{ADEs}^{45}$. Around $70 \%$ of our participants reported informing their physicians about their experienced ADEs. This percentage falls within the range reported in published literature where proportions of patients who claimed informing their physicians about their ADRs ranged between 54 and $87 \%$ of respondents ${ }^{46,47}$. Reasons that our participants stated for not informing their physicians include their inability to reach the physician or them not 
being adequately instructed to report. Physicians hold a key responsibility in educating patients about ADEs and the importance of reporting ADEs as they occur, as well as in facilitating the communication and the reporting mechanism. A study examining barriers and facilitators of adverse event reporting by adolescent patients and their families showed that the quality of healthcare experience and the type of communication with the healthcare provider influenced patient reporting ${ }^{48}$.

In our findings, the occurrence of ADEs was positively associated with the number of daily medications taken, and the use of an injectable medication. The association between the number of medications taken and the self-reported ADEs is documented in the literature ${ }^{19}$. There is no evidence that intake of injectable medications is associated with higher ADRs, but research shows that the incidence of errors with injectable medications is higher than with other forms of medications ${ }^{49}$. Patients who reported experiencing ADEs also reported asking about possible interactions with prescribed medications while getting the OTC's from the pharmacy. This association can be explained by the fact that patients who experience more ADEs may become more concerned about potential drug interactions. In addition, patients who received counseling from their physicians regarding missing drug doses, and who received medication counseling before hospital discharge reported experiencing less ADEs. In fact, studies have shown an association between discharge counseling and lower rates of adverse drug events and hospital re-admission ${ }^{50,51}$.

Our findings show that significantly more outpatients reported receiving counseling from pharmacists as compared to physicians regarding elements of medication use. In fact, physicians commonly fail to provide appropriate counseling about prescription medications $\mathrm{s}^{52-55}$. One of the main reported physicians' expectations from pharmacists in primary care was to provide more education and counseling about medications $s^{56,57}$. While pharmacists have a professional responsibility to provide patient counseling, physicians can assume a bigger role in providing medication counseling.

To our knowledge, this is the first study in the Lebanese population, on a national scale, that addresses selfreported experience of ADEs. In fact, there are differences among countries in the occurrence of ADRs due to many differences including diseases, prescribing patterns, genetics, and drug distribution. Data derived from within the country may have greater relevance and educational value and may encourage national regulatory decision-making ${ }^{58}$.

Study limitations. Our study population consisted of outpatients visiting the community pharmacies to procure their medications, which excludes patients who acquire their medications from dispensaries, and patients with lower healthcare accessibility. There is also potential information bias. The patients' experience of ADEs assessed in our study was self-reported, and was not verified or confirmed by our investigators using objective evidence.

At the time investigators conducted this study, there was no active national pharmacovigilance center in Lebanon, through which healthcare professionals or patients can report ADEs. ADEs were not reported, analyzed, or registered centrally. Following the completion of this study, the medication safety subcommittee of the OPL created an electronic platform for pharmacists to report $\mathrm{ADRs}^{59}$. This platform remains inactive until date due to poor reporting. Moreover, the Lebanese University-School of pharmacy had established in 2004 a center for Adverse Events of Drug Monitoring that remained inactive until 2020. A collaborative agreement between the Lebanese University and the Ministry of Public Health (MOPH) reactivated the center (ministerial decree $427 / 1$ ) and authorized it to function officially as the national pharmacovigilance center. Stakeholders have just completed all the preparations and documentations needed to launch the center for service in 2021 and become a full member in the Uppsala network ${ }^{60}$.

\section{Conclusions}

Our study showed prevalence of ADEs among Lebanese outpatients especially patients with polypharmacy, and suggested that patients do not report all the ADEs to their physicians. Patients should be educated on the importance of reporting ADEs to their primary healthcare provider. Reporting helps preventing future ADEs, contributes to the public knowledge and medical literature, and encourages national regulatory decision-making. There is need to assess potential preventability of these ADEs through proper follow-up and monitoring, in an attempt to reduce potential patient harm and healthcare costs. Studies assessing Lebanese inpatients experience of ADEs can complement this data throughout the continuum of healthcare, and can drive evidence-based decision-making.

\section{Data availability}

The datasets used and/or analyzed during the current study are available from the corresponding author on reasonable request.

Received: 29 July 2020; Accepted: 24 March 2021

Published online: 12 April 2021

\section{References}

1. World Health Organization. 10 Patient Safety Facts. https://www.who.int/features/factfiles/patient_safety/en/ (2018). Accessed 1 June 2019.

2. Leape, L. L. et al. The nature of adverse events in hospitalized patients. Results of the Harvard Medical Practice Study II. N. Engl. J. Med. 324, 377-384 (1991).

3. Leape, L. L., Kabcenell, A., Berwick, D. M. \& Roessner, J. Reducing adverse drug events. Breakthrough series Guide Institute for Healthcare Improvement, Boston, 84-91 (1998). 
4. Committee of Experts on Management of Safety and Quality in Health Care (SP-SQS) Expert Group on Safe Medication Practices. Glossary of terms related to patient and medication safety https://www.who.int/patientsafety/highlights/COE_patient_and_medic ation_safety_gl.pdf. (2005).

5. Pillans, P. I. Clinical perspectives in drug safety and adverse drug reactions. Exp. Rev. Clin. Pharmacol. 1(5), 695-705 (2008).

6. Breckenridge, A. The burden of adverse drug events. Br. J. Clin. Pharmacol. 80(4), 785-787 (2015).

7. Morimoto, T., Gandhi, T. K., Seger, A. C., Hsieh, T. C. \& Bates, D. W. Adverse drug events and medication errors: detection and classification methods. Qual. Saf. Health Care 13(4), 306-314 (2004).

8. Mayer, M. H., Dowsett, S. A., Brahmavar, K., Hornbuckle, K. \& Brookfield, W. P. Reporting Adverse drug events. US Pharm. 35 , HS-15-HS-19 (2010).

9. Van Grootheest, K. \& de Jong-van den Berg, L. Patients' role in reporting adverse drug reactions. Exp. Opin. Drug. Saf. 3(4), 363-368 (2004).

10. European Medicines Agency (2015). Pharmacovigilance. https://www.ema.europa.eu/en/documents/leaflet/pharmacovigilance en.pdf

11. U.S. Department of Health and Human Services, Office of Disease Prevention and Health Promotion. 2014. National Action Plan for Adverse Drug Event Prevention. Washington, DC: Author.

12. Cox, A. Involving patients in reporting adverse drug reactions should be welcomed. Pharm. J. 282, 16 (2009).

13. Wysowski, D. K. \& Swartz, L. Adverse drug event surveillance and drug withdrawals in the United States, 1969-2002: the importance of reporting suspected reactions. Arch. Intern. Med. 165(12), 1363-1369 (2005).

14. Gandhi, T. K. et al. Drug complications in outpatients. J. Gen. Intern. Med. 15(3), 149-154 (2000).

15. Hazell, L. \& Shakir, S. A. Under-reporting of adverse drug reactions: a systematic review. Drug Saf. 29(5), 385-396. https://doi. org/10.2165/00002018-200629050-00003 (2006).

16. Shehab, N. et al. US emergency department visits for outpatient adverse drug events, 2013-2014. JAMA 316(20), 2115-2125 (2016).

17. Bouvy, J. C., De Bruin, M. L. \& Koopmanschap, M. A. Epidemiology of adverse drug reactions in Europe: a review of recent observational studies. Drug Saf. 38(5), 437-453 (2015).

18. Hakkarainen, K. M. et al. Prevalence, nature and potential preventability of adverse drug events-a population-based medical record study of 4970 adults. Br. J. Clin. Pharmacol. 78(1), 170-183 (2014).

19. Gurwitz, J. H. et al. Incidence and preventability of adverse drug events among older persons in the ambulatory setting. JAMA 289, 1107-1116 (2003).

20. Hakkarainen, K. M. et al. Prevalence and perceived preventability of self-reported adverse drug events - a population-based survey of 7099 adults. PLoS ONE 8(9), e73166 (2013).

21. Lee, C. Y. et al. Prevalence of medication-related risk factors among retirement village residents: a cross-sectional survey. Age Ageing 39(5), 581-587 (2010).

22. Oladimeji, O. et al. risk factors for self-reported adverse drug events among medicare enrollees. Ann. Pharmacother. 42(1), 53-61 (2008).

23. Miller, G. C., Britt, H. C. \& Valenti, L. Adverse drug events in general practice patients in Australia. Med. J. Aust. 184, 321-324 (2006).

24. Sales, I. et al. Public awareness and perception toward adverse drug reactions reporting in Riyadh Saudi Arabia. Saudi Pharm J. 25(6), 868-872 (2017).

25. Al Dweik, R. et al. Factors affecting patient reporting of adverse drug reactions: a systematic review. Br. J. Clin. Pharmacol. 83, 875-883 (2017).

26. Ghusn, H. Polypharmacy: what clinicians need to know while caring for an elderly. J. Med. Liban. 60(4), 207-213 (2012).

27. Zeenny, R., Wakim, S. \& Kuyumjian, Y.-M. Potentially inappropriate medications use in community-based aged patients: a crosssectional study using 2012 Beers criteria. Clin. Interv. Aging 12, 65-73 (2017).

28. El Khoury, G., Ramia, E. \& Salameh, P. Misconceptions and malpractices toward antibiotic use in childhood upper respiratory tract infections among a cohort of Lebanese parents. Eval. Health Prof. 41(4), 493-511 (2018).

29. Hallit, S., Zahreddine, L., Saleh, N., Shakaroun, S. \& Lahoud, N. Practice of parents and pharmacists regarding antibiotics use in pediatrics: a 2017 cross-sectional study in Lebanese community pharmacies. J. Eval. Clin. Pract. 26(1), 181-189 (2020).

30. Ramia, E. \& Zeenny, R. Completion of therapeutic and safety monitoring tests in Lebanese outpatients on chronic medications: a cross-sectional study. Patient Prefer Adherence 8, 1195-1204 (2014).

31. Ramia, E. et al. Assessment of patients' knowledge and practices regarding their medication use and risks in Lebanon. Int. J. Clin. Pharm. 39(5), 1084-1094 (2017).

32. El-Jardali, F. et al. The current state of patient safety culture in Lebanese hospitals: a study at baseline. Int. J. Qual. in Healthc. 22(5), 386-395 (2010).

33. El-Jardali, F. et al. Predictors and outcomes of patient safety culture in hospitals. BMC Health Serv. Res. 11(45), 386-395 (2011).

34. Hallit, S. et al. Order of Pharmacists of Lebanon scientific committee-Medication safety subcommittee. Medication safety knowledge, attitude, and practice among hospital pharmacists in Lebanon. J. Eval. Clin. Pract. 25(2), 323-339 (2019).

35. Awada, S. et al. Awareness and perception of national pharmacovigilance center among lebanese medical Staff. J. Pharmacovigil. 4, 199 (2016).

36. Hajj, A. et al. Order of Pharmacists Scientific Committee-Medication Safety Subcommittee. Medication safety knowledge, attitudes and practices among community pharmacists in Lebanon. Curr. Med. Res. Opin. 34(1), 149-156 (2018).

37. NHS (National Health Service-England). National patient survey program. National results from the 2014 Inpatient Survey. http:// www.cqc.org.uk/sites/default/files/201500519\%20NHS\%20Inpatient\%20Survey\%202014\%20National\%20summary\%20and\%20res ults\%20tables\%20FINAL.pdf. Accessed 1 June 2019 (2014).

38. World Health Organization Regional Office for Europe. 2013. Exploring patient participation in reducing health-care-related safety risks. DK-2100 Copenhagen, Denmark.

39. Gandhi, T. K. et al. Adverse drug events in ambulatory care. N. Engl. J. Med. 348, 1556-1564 (2003).

40. World Fact Book of the United States Central Intelligence Agency. Lebanon Demographics Profile 2014. http://www.indexmundi. com/lebanon/demographics_profile.html (2016).

41. Bent, S., Padula, A. \& Avins, A. L. Brief communication: better ways to question patients about adverse medical events: a randomized, controlled trial. Ann. Intern. Med. 144(4), 257-261 (2006).

42. Adisa, R., Adeniyi, O. R. \& Fakeye, T. O. Knowledge, awareness, perception and reporting of experienced adverse drug reactions among outpatients in Nigeria. Int. J. Clin. Pharm. 41(4), 1062-1073 (2019).

43. Hedna, K. et al. Refill adherence and self-reported adverse drug reactions and sub-therapeutic effects: a population-based study. Pharmacoepidemiol. Drug Saf. 22(12), 1317-1325 (2013).

44. Almubark, R. A. et al. National cross-sectional study of community-based adverse drug reactions in Saudi Arabia. Drugs Real World Outcomes 7, 161-170. https://doi.org/10.1007/s40801-020-00186-8 (2020).

45. Zaman Huri, H. \& Chai Ling, L. Drug-related problems in type 2 diabetes mellitus patients with dyslipidemia. BMC Public Health 13, $1192(2013)$.

46. Hariraj, V. \& Aziz, Z. Patient reporting of adverse drug reactions (ADRs): survey of public awareness and predictors of confidence to report. Ther. Innov. Regul. Sci. 52(6), 757-763. https://doi.org/10.1177/2168479017745025 (2018). 
47. Golomb, B. A. et al. Physician response to patient reports of adverse drug effects: implications for patient-targeted adverse effect surveillance. Drug Saf. 30(8), 669-675 (2007).

48. Sawhney, P. N. et al. Barriers and facilitators of adverse event reporting by adolescent patients and their families. J. Patient Saf. https://doi.org/10.1097/PTS.0000000000000290 (2017).

49. Cousins, D. H. et al. Medication errors in intravenous medicine preparation and administration: a multicentre audit in the UK, Germany and France. Qual Saf Health Care 14, 190-195 (2005).

50. Schnipper, J. L. et al. Role of pharmacist counseling in preventing adverse drug events after hospitalization. Arch. Intern. Med. 166, 565-571 (2006).

51. Phatak, A. et al. Pharmacist impact on transitional care. J. Hosp. Med. 1, 39-44 (2016).

52. Kripalani, S. et al. Development and evaluation of a medication counseling workshop for physicians: can we improve on "take two pills and call me in the morning"?. Med. Educ. Online https://doi.org/10.3402/meo.v16i0.7133 (2011).

53. Golin, C. E., Smith, S. R. \& Reif, S. Adherence counseling practices of generalist and specialist physicians caring for people living with HIV/AIDS in North Carolina. J. Gen. Intern. Med. 19, 16-27 (2004).

54. Tarn, D. M. et al. Physician communication when prescribing new medications. Arch. Intern. Med. 166, 1855-1862 (2006).

55. Chillinger, D. et al. Functional health literacy and the quality of physician-patient communication among diabetes patients. Patient Educ. Couns. 52, 315-323 (2004).

56. Dupotey Varela, N. M. et al. What is the role of the pharmacist? Physicians' and nurses' perspectives in community and hospital settings of Santiago de Cuba. Braz. J. Pharm. Sci. 47(4), 709-718 (2011).

57. Kelly, D. V. et al. Pharmacist and physician views on collaborative practice: findings from the community pharmaceutical care project. Can. Pharm. J. CPJ 146(4), 218-226 (2013).

58. World Health Organization. Quality Assurance and Safety of Medicines Team. Safety of medicines: a guide to detecting and reporting adverse drug reactions: why health professionals need to take action. World Health Organization. https://apps.who.int/ iris/handle/10665/67378 (2002).

59. Akel, M. et al. The Lebanese Order of Pharmacists' Scientific Committee-Medication Safety Subcommittee. Medication Safety Spontaneous Reporting System: the Lebanese Order of Pharmacists Initiative. Bull. Fac. Pharm. Cairo Univ. https://doi.org/10. 1016/j.bfopcu.2019.02.001 (2019).

60. Republic of Lebanon Ministry of Public Health (MOPH). Pharmacovigilance System in Lebanon. Available from https://www. moph.gov.lb/en/Pages/4/6642/quality-assurance-of-pharmaceutical-products\#/en/view/44743/pharmacovigilance-system-leban on (2021).

\section{Acknowledgements}

The authors would like to thank all the inspectors of the Order of Pharmacists in Lebanon (OPL) for their help in passing the questionnaires and data entry. The authors would also like to thank the members of the OPL Medication Safety Subcommittee for their contribution, namely Aline Hajj, Maryam Ghorayeb, Marwan Akel, Hayat Azouri, Hind Hajj, Nouhad Sarkis, Hadi Sherri and Patricia Shuhaiber.

\section{Author contributions}

E.R., R.Z., S.H., and P.S. have been heavily involved in the conception and design of the study, and have contributed significantly in the drafting of the manuscript. E.R., R.Z., and P.S. were mainly involved in the analysis and interpretation of the data. All authors agree to be accountable for all aspects of the work.

\section{Competing interests}

The authors declare no competing interests.

\section{Additional information}

Correspondence and requests for materials should be addressed to E.R.

Reprints and permissions information is available at www.nature.com/reprints.

Publisher's note Springer Nature remains neutral with regard to jurisdictional claims in published maps and institutional affiliations.

(c) (i) Open Access This article is licensed under a Creative Commons Attribution 4.0 International License, which permits use, sharing, adaptation, distribution and reproduction in any medium or format, as long as you give appropriate credit to the original author(s) and the source, provide a link to the Creative Commons licence, and indicate if changes were made. The images or other third party material in this article are included in the article's Creative Commons licence, unless indicated otherwise in a credit line to the material. If material is not included in the article's Creative Commons licence and your intended use is not permitted by statutory regulation or exceeds the permitted use, you will need to obtain permission directly from the copyright holder. To view a copy of this licence, visit http://creativecommons.org/licenses/by/4.0/.

(C) The Author(s) 2021 